\title{
Drying of Salt Solutions from Porous Media: Effect of Surfactants
}

\author{
Mohsin J. Qazi ${ }^{1}$ - Daniel Bonn ${ }^{1} \cdot$ Noushine Shahidzadeh ${ }^{1}$
}

Received: 6 May 2018 / Accepted: 24 September 2018 / Published online: 5 October 2018

(c) The Author(s) 2018

\begin{abstract}
The evaporation of salt $(\mathrm{NaCl})$ solutions from porous media is studied in the presence of surfactants, because surfactants are often used as cleaning agents for salt-contaminated stones. We show that, contrary to what is commonly assumed, the presence of the surfactant and the changed wetting properties do not affect the drying kinetics: The impact of the surfactants is rather that of a crystallization modifier for the salt. Upon adding a cationic or nonionic surfactant to salt solution, the drying rate is unchanged initially, but can slow down dramatically at later times due to the formation of a salt crust at the surface. When this happens, the total drying time increases compared to pure $\mathrm{NaCl}$ solutions without surfactants, at least for very porous stones for which the pores become completely blocked. Surprisingly, for a low-porosity stone the small pores at the surface remain open. The longer drying time for the large porosity stone increases the risk of, e.g., frost or fungal damage to the stones. Consequently, the use of surfactants in conservation treatments should be done with caution.
\end{abstract}

Keywords Drying kinetics $\cdot$ Surfactants $\cdot$ Efflorescence $\cdot$ Sandstones $\cdot$ Crystallization modifiers

\section{Introduction}

Drying of saturated porous media is a widely studied phenomenon owing to its relevance to soil mechanics, food production, carbon dioxide sequestration, etc. (Rad et al. 2015; Eloukabi et al. 2013; Shahidzadeh-Bonn et al. 2007; Yiotis et al. 2003; Coussot 2000). Recently, it also received significant attention from the fields of building physics and cultural heritage conservation (Desarnaud et al. 2015; Derluyn et al. 2014). Buildings made of porous materials often become saturated by water along with salts from various sources like rain, groundwater uptake, marine sprays, salts sprayed for deicing of roads and cleaning processes. This invasion of salt solutions is eventually followed by drying and concomitant crystallization of the dissolved salts. The latter significantly influence the drying kinetics of porous structures, and previous studies have reported counterintuitive trends in drying kinetics when salts are present

Mohsin J. Qazi

m.j.qazi@uva.nl

1 Institute of Physics, University of Amsterdam, Science Park 904, 1098 XH Amsterdam, The Netherlands 
(Veran-Tissoires et al. 2012; Desarnaud et al. 2015; Shokri-Kuehni et al. 2017; Bergstad and Shokri 2016; Bergstad et al. 2017). Depending on the environmental conditions, the salt precipitation can alter the drying process by forming a salt crust that blocks the evaporation from the core of the stones (Desarnaud et al. 2015; Gupta et al. 2014; Grementieri et al. 2017). This often happens at low relative humidity, where the initial drying is rapid. On the other hand, for drying at higher relative humidity, different salt precipitation dynamics at the surface enables continuous hydraulic conductivity and can even enhance the evaporation process (Desarnaud et al. 2015; Gupta et al. 2014; Shokri-Kuehni et al. 2017; Veran-Tissoires et al. 2012). This then leads to the counterintuitive result that the total drying time can be longer at a low relative humidity. Other than environmental conditions, salt crystallization is also affected by the nature of the salt and the porous material, like its porosity, pore size distribution, and wetting properties (Rad et al. 2015; Eloukabi et al. 2013; Bergstad and Shokri 2016; Bergstad et al. 2017).

In addition, the environmental fluctuations, which lead to repeated cycles of drying and wetting, have been identified as a major cause of deterioration of building structures. The crystallization, which takes place during the drying process, can occur either on the surface of the stones in the form of 'efflorescence' or inside the porous structure known as 'subflorescence' (Nachshon et al. 2011). Both these modes of crystallization are detrimental to the mechanical strength and aesthetics of the buildings. The aspect of damage by subflorescence and efflorescence has been investigated in significant detail (Desarnaud et al. 2013, 2016; Flatt et al. 2014; Steiger 2005; Veran-Tissoires et al. 2012; Sghaier and Prat 2009). However, little attention has been invested in accounting for the damage resulting from the prolonged entrapment of moisture in porous structures. In this context, the drying kinetics of building structures is an important subject, as the time for which the stones remain saturated with water contributes to the susceptibility of these structures to frost damage (Winkler 1968) and biological attack from various algae (Vojtková 2017). Altering various parameters like the wettability of the porous media, pore size distributions and different environmental conditions have thus revealed very useful insights into the drying kinetics of porous stones yielding prospects to control it favorably.

Surfactants are popular ingredients in cleaning products. As a result, they inevitably end up in the buildings along with salts. Surfactants are amphiphilic compounds with the versatile property of adsorbing at the interfaces of different phases (hydrophilic and hydrophobic). In this way, they are known to lower the liquid/vapor and solid/liquid surface tensions and improve the spreading properties of the liquid.

However, apart from wettability enhancers, surfactants can also act as crystallization modifiers (Rodriguez-Navarro et al. 2000; Sonin et al. 1998; Myatt et al. 1994; Qazi et al. 2017; Chen et al. 2015). Surfactants, by virtue of their ability to adsorb at the interfaces, can preferentially adsorb on selective crystal faces, thereby altering their overall shape, size and other properties. Surfactants have also been shown to act as nucleation inhibitors; because they can passivate impurities by absorbing on them, they can induce high supersaturations (Qazi et al. 2017) prior to salt precipitation. The latter can lead to serious consequences as the crystals forming at higher supersaturation could eventually exert an even higher crystallization pressure (Flatt et al. 2007; Espinosa-Marzal and Scherer 2010). This potential of additives to influence the crystallization phenomenon has drawn the interest of researchers from the crystallization field to study surfactants more extensively (Lubelli and van Hees 2007). Notably, different surfactants have a different influence on the wettability (Afsar-Siddiqui et al. 2004; Beacham et al. 2009) and the crystallization behavior of salts; hence, the choice of surfactants to be used in cleaning product is of crucial importance. Despite their very common use and ubiquitous presence, the influence of surfactants on the drying of porous media has not been 
Table 1 Characteristics of sandstones used in this study obtained by mercury intrusion porosimetry

\begin{tabular}{llcl}
\hline Sandstones & Porosity $\phi(\%)$ & Pore diameter $D_{\mathrm{p}}(\mu \mathrm{m})$ & $V_{\mathrm{p}} / S_{\mathrm{e}}$ of samples \\
\hline Fontainebleau & 7.6 & 8 & 0.12 \\
Mesne & 29 & 15 & 0.5 \\
\hline
\end{tabular}

$V_{\mathrm{p}} / S_{\mathrm{e}}$ represents the ratio of the pore volume to total evaporative surface area of the cylinder $(9 \times 8 \mathrm{~mm})$ excluding the bottom

studied so far. In this study, we test the influence of different surfactant types on the drying of sodium-chloride-contaminated sandstones with a high (Mesne sandstone) and a low porosity (Fontainebleau sandstone).

\section{Experimental}

The drying experiments were carried out on two types of sandstones, Prague (Mešne) and Fontainebleau. Both of the stones have an identical mineral composition ( $90 \%$ quartz and $10 \%$ clay minerals) so that any differences in their behavior must be due to the geometry of the pore network. The characteristics of the two stones analyzed by mercury intrusion porosimetry are summarized in Table 1 (Desarnaud et al. 2015; Lubelli and van Hees 2007). Prior to the experiments, the stones were cut into cylinders [length $9 \mathrm{~mm}(L)$ and diameter $8 \mathrm{~mm}(D)]$. Next, the cylinders were dried in an oven, at $100{ }^{\circ} \mathrm{C}$ for 2 days, in order to make sure the whole sample was completely dry before being subjected to controlled wetting and drying.

The influence of surfactants on the drying of saline solutions in sandstones was investigated by measuring the evaporation rate of surfactant-salt solution in the sandstones while keeping the pure $\mathrm{NaCl}$ solution as control. $\mathrm{NaCl}$ of $99 \%$ purity as supplied by Sigma-Aldrich was used to make an aqueous solution close to solubility [5.5 m, the molality $(m)$ is defined as the number of moles of solute per kilogram of solvent]. Only those surfactants were used that were stable at $5.5 \mathrm{~m} \mathrm{NaCl}$ solution, as reported in an earlier study (Qazi et al. 2017). The two surfactants used were: cationic surfactant cetyltrimethylammonium bromide (CTAB) (critical micelle concentration $\mathrm{CMC}=0.9 \mathrm{E}-3 \mathrm{M}, 99 \%$ purity, Sigma-Aldrich) and a nonionic surfactant Tween $80(\mathrm{CMC}=10 \mathrm{mg} / \mathrm{l}$, proteomics grade purity, Amresco Ltd). We have been unable to find an anionic surfactant that remains stable in solution for these high concentrations of salt. Firstly, pure surfactant solutions at the critical micelle concentration were prepared with demineralized water from millipore. Subsequently, the ternary surfactant-salt solutions were made by adding $\mathrm{NaCl}$ corresponding to $5.5 \mathrm{~m}$ to the prepared surfactant solutions. After preparation, the solutions were stirred and left to stabilize for at least one night. The liquid/air surface tension $\left(\gamma_{\text {lv }}\right)$ of these solutions was measured using Kruss EasyDrop tensiometer. The addition of surfactants reduces the surface tension of the $\mathrm{NaCl}$ solution from 81 to $32 \mathrm{mN} / \mathrm{m}$ in the presence of CTAB and to $40 \mathrm{mN} / \mathrm{m}$ in case of Tween 80 . In principle, the change in surface tension translates into change in the wettability. However, the change in wettability strongly depends upon the surface properties of the substrate. In this case, we could not measure contact angles on the pure material of stone itself because of the pores. However, on a glass substrate (similar chemistry to sandstone), the contact angle of $5.5 \mathrm{~m}$ $\mathrm{NaCl}$ was around 25 degrees. When $\mathrm{CTAB}$ was present with $\mathrm{NaCl}$, the contact angle was measured to be around 33 degrees and with Tween 80, it was around 23 degrees. Hence, 
it can be said that surfactants, when present in high salt concentrations, do not change the contact angles significantly.

The drying experiments were performed after saturating the sandstone samples with the solutions by capillary imbibition using a vacuum pump. The samples were then left to dry (except from the bottom side) on a mass balance with enclosures, installed in a climatic chamber while recording the mass at intervals of $30 \mathrm{~s}$. To ensure a minimum directional flow of the air around the sample, the air supply to the climatic chamber was installed at the lower part of the chamber and from opposite sides; the experiments were done at a constant temperature $\left(21{ }^{\circ} \mathrm{C}\right)$ and at two different relative humidities: $60 \%$ and $20 \%$, representative of summer and winter weather conditions, respectively. In order to determine the influence of surfactants alone on the drying rate, control experiments using pure water-surfactant solutions were also carried out. All the experiments were performed at least 5 times in order to check the reproducibility of the drying mechanisms.

After completion of the drying process, the morphology of the efflorescence was imaged using a Hitachi tabletop scanning electron microscope (SEM). In order to visualize the occurrence of subflorescence, the samples were carefully cracked open and the inside of the samples was imaged by SEM.

\section{Results and Discussion}

\subsection{Prague Sandstone (High Porosity)}

\subsubsection{Drying at Summer Weather Conditions (RH 60\%)}

The measurement of the weight of the sample allows (by subtracting the stone and salt mass) to monitor the amount of water as a function of drying time. We plot the normalized mass $\left(\mathrm{m} / \mathrm{m}_{0}\right)$ enabling us to compare the drying trends in samples with slightly different uptake volumes. The results for a high relative humidity (RH) of 60\%, shown in Fig. 1, reveal that the pure $\mathrm{NaCl}$ solution follows a constant drying rate until the sample is completely dry. This drying behavior shows that the solution is driven by capillarity to the surface of the stone sample where the diffusion of water molecule in the surrounding air limits the evaporation flux until the end of the drying. The continuous capillary connections are enabled by the fact that evaporation taking place at the surface induces flux of liquid toward the surface and as long as the evaporative flux is lesser or equal to the capillary rise, the capillary connections would remain intact (Le Bray and Prat 1999; Guglielmini et al. 2008). In addition, with higher salt concentration, like used in the current study, the continuity of capillary connections is more likely than in the cases where salts are present in lower concentrations (Bergstad et al. 2017). This is mainly due to the type of crystal precipitation at the surface (Fig. 2). Zooming on the surface reveals that salt precipitation at the surface does not clog the pores of the stone, which is in agreement with previous studies (Veran-Tissoires et al. 2012; Desarnaud et al. 2015; Shokri-Kuehni et al. 2017). In addition, SEM images of the efflorescence pattern show assemblies of $\mathrm{NaCl}$ microcrystallites, which grow perpendicular to the surface of the stone in a house of cards-like structure with many voids (cauliflower-like) (Shahidzadeh-Bonn et al. 2008). The internal porous structures of the precipitated salt, with smaller pores, play as a sink and help to pump out the liquid for further evaporation. At high salt concentration, the salt precipitation will start earlier and more homogeneously on the total surface, explaining 

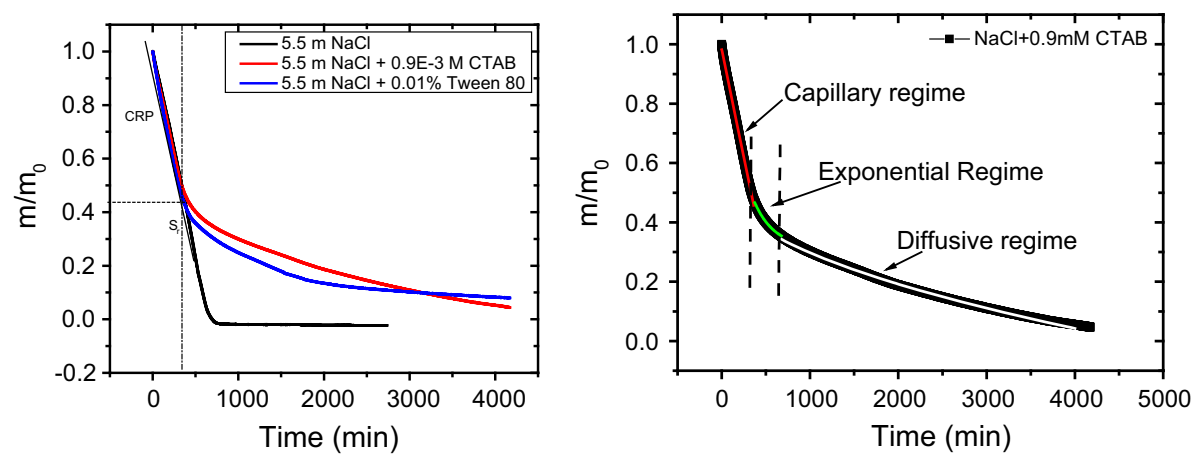

Fig. 1 Left: the time evolution of the saturation $\left(m_{t} / \mathrm{m}_{0}\right)$ in Prague sandstone samples $(8 \times 9 \mathrm{~mm})$ at $\mathrm{RH}=$ $60 \%$ : pure $\mathrm{NaCl}$ solution (black line), $\mathrm{NaCl} / \mathrm{CTAB}$ (red), and $\mathrm{NaCl} /$ Tween 80 (blue). The capillary regime has an evaporation rate $(\mathrm{CRP})$ of $\mathrm{d} m / \mathrm{d} t \sim 0.2 \mathrm{mg} / \mathrm{min}$. Right: the three stages of evaporation: capillary, exponential, and diffusive defined for the salt and CTAB solution. (Capillary regime: $m / m_{0}=0.98-0.001 t ; R^{2}=0.99$; exponential regime: $m / \mathrm{m}_{0}=0.31+0.78 \exp (-0.004 t) ; R^{2}=0.99$; diffusive regime: $m / m_{0}=0.55-0.008 \sqrt{ } t$; $R^{2}=0.99$.)

why the continuity of capillary connections is more feasible at high salt concentration as reported earlier (Bergstad et al. 2017).

In contrast to pure $\mathrm{NaCl}$, when surfactants are added to the salt solution, the total drying of the sample slows down dramatically. With surfactants, the drying mechanism results in the emergence of three drying stages (capillary, exponential, diffusive) as it has been observed previously for evaporation of pure salt solutions but at low relative humidity (Desarnaud et al. 2015), as shown in Fig. 1. However, here because the exponential regime remains very small compared to the two other regimes, we will focus more on the capillary (first regime) and diffusive regimes (third regime) in the rest of analysis of the results. In the first capillary stage, $60 \%\left(S_{\mathrm{r}} \sim 0.4\right)$ of the initial salt solution evaporated with a constant drying rate (CRP) equivalent to the pure $\mathrm{NaCl}$ solution $\mathrm{d} m / \mathrm{d} t \sim 0.2 \mathrm{mg} / \mathrm{min}$ ), irrespective of the surfactant. However, beyond this stage, surprisingly the drying slows down dramatically and the rate is no longer constant.

Surprisingly, the analysis of SEM images of the stones (post-drying) reveals a different crystallization pattern in the presence of surfactants: A rather non-uniform lateral growth of microcrystallites can be observed. The surface of crystallites advances by the lateral motion of steps which are one interplanar spacing in height (Fig. 3). The growth rate of steps in the presence of impurities was previously calculated using step pinning theory (Yang et al. 2012). The lateral growth of several microcrystallites at different locations gradually decreases the evaporative surface area and leads to the formation of a crust (skin) as soon as the steps of adjacent growing crystals join each other (Fig. 6). Although the salt crust also has some pores due to defective joints between laterally grown microcrystallites, their size $(\sim 2-5 \mu \mathrm{m})$ and number are much smaller than the porous network of the stone and reduce dramatically the evaporation flux (Fig. 3). Clogging of the stone pores by the low-porosity salt skin clearly prevents the transport of the salt solution to the evaporative surface.

Therefore, by linking the SEM images to the saturation measurements, the two major stages of evaporation can be interpreted as follows. At first, there are pathways for the solution to arrive from within the stone to the surface from where it evaporated; there the evaporation induced the precipitation of microcrystallites which grow laterally and join each other and that made up the crust. This period corresponds to an exponential decrease in the 

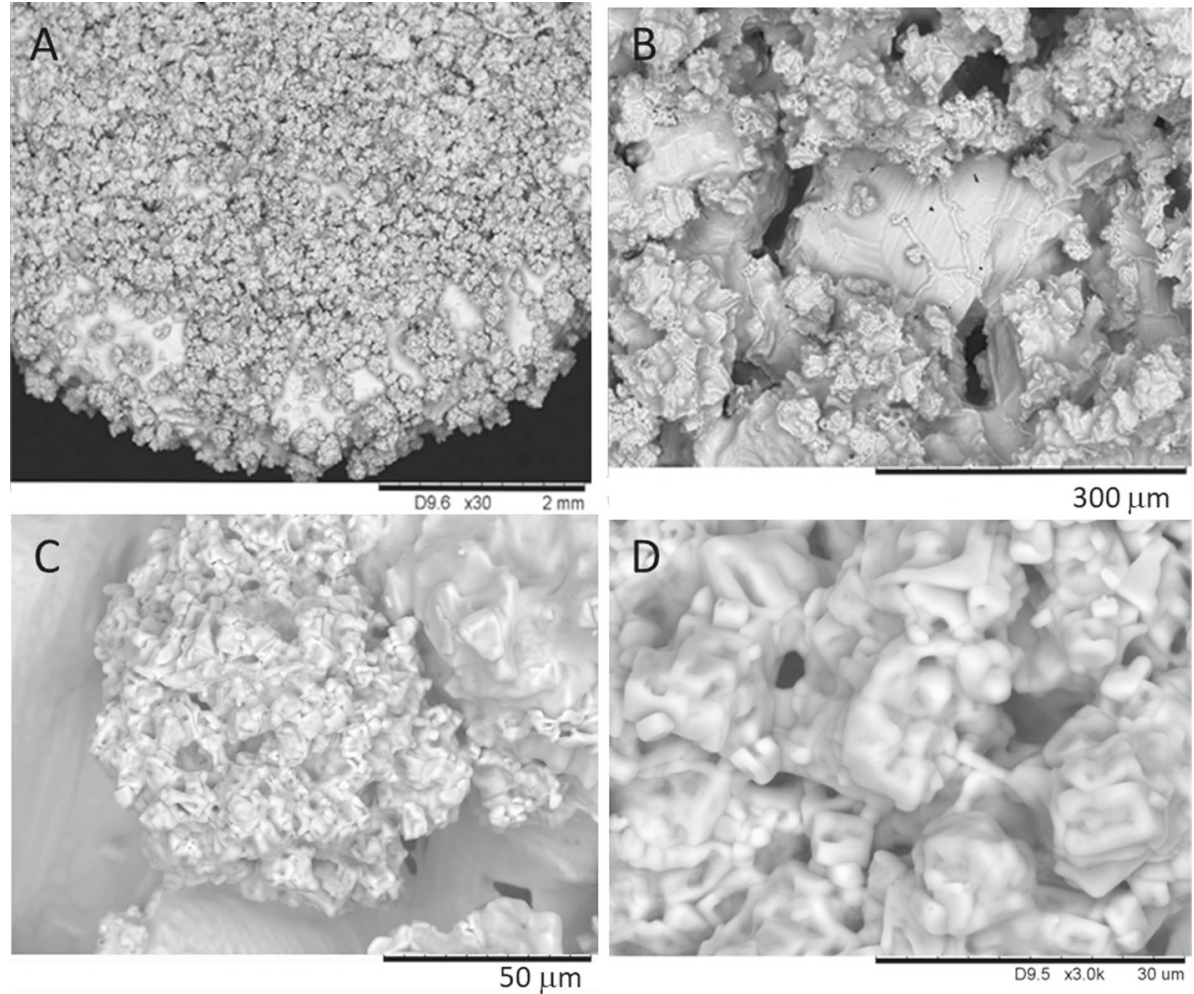

Fig. 2 Crystal precipitation when pure $\mathrm{NaCl}$ solution has evaporated in Prague sandstone. $\mathbf{a}$, b showing open pores of the stone; $\mathbf{c}, \mathbf{d}$ the porous structure (pore size of 2-5 $\mu \mathrm{m}$ ) of the house of cards-like precipitation of several microcrystallites at the surface as efflorescence

mass as described in Desarnaud et al. 2015. At a certain moment, the salt crust growing on the surface became extended enough to cover most of the pores on the surface, resulting in the clogging of many of the liquid pathways and hence a switch to diffusion-limited solution transfer through the crust. We know from earlier studies that the rate of diffusive transport through the salt crust varies as the square root of time (Desarnaud et al. 2015). The origin and more detailed treatment of the equation are provided in (Desarnaud et al. 2015).

$$
\Delta m_{\mathrm{w}}=\left(m-m_{0}\right)=-\left(\frac{2 D_{\mathrm{s}} M \Delta p_{\mathrm{w}} \rho_{\mathrm{NaCl}} S^{2}}{0.36 R T}\right)^{1 / 2} \cdot t^{1 / 2} .
$$

Here, $\Delta m_{\mathrm{w}}$ is the weight of water that is evaporated from the salt crust surface after diffusing through it. $M$ is the molar mass, $D_{\mathrm{S}}$ is the diffusion coefficient on the skin, $\Delta p_{\mathrm{w}}$ is the difference in vapor pressure between the inner and outer side of the crust, $S$ is the free evaporative surface, $\rho_{\mathrm{NaCl}}$ is the salt concentration, $R$ is the gas constant, $T$ is the temperature, and $t$ is the time.

According to this model, the limiting factor for the drying kinetics is the presence of a salt crust, and the water vapor diffusion through this crust, so that the relative humidity in the environment becomes less relevant.

Upon fitting our experimental data with the diffusive transport model, we obtain again a very good agreement (Fig. 1, right). 

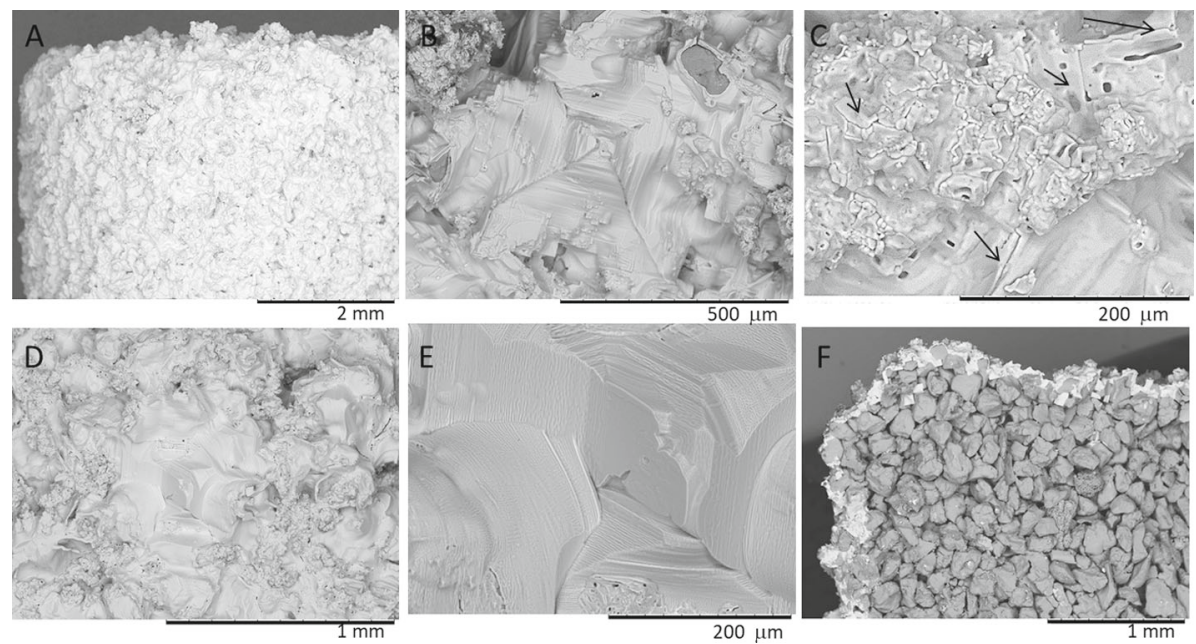

Fig. 3 Morphology of $\mathrm{NaCl}$ efflorescence formed at the surface at the end of drying in the presence of surfactants: a showing a salt crust of low porosity covering the sample. b, $\mathbf{c ~ N a C l / C T A B}$ solution. d, e $\mathrm{NaCl} / \mathrm{Tween}$ 80 solution: b, e showing the lateral growth of steps for one crystallite, $\mathbf{c}$ the defective joints between different crystallites; f cross section of the sample showing the salt skin: salt crust at the surface and crystallization in the subsurface

Fig. 4 Drying at RH $60 \%$ of Prague sandstones saturated with pure water (blue symbols), aqueous surfactant solutions (red for CTAB, purple for Tween 80 ) ( $\mathrm{dm} / \mathrm{dt} \sim 0.5 \mathrm{mg} / \mathrm{min})$. The curve for the $\mathrm{NaCl}$ solution (black) is added for comparison ( $\mathrm{dm} / \mathrm{dt} \sim 0.2 \mathrm{mg} / \mathrm{min})$

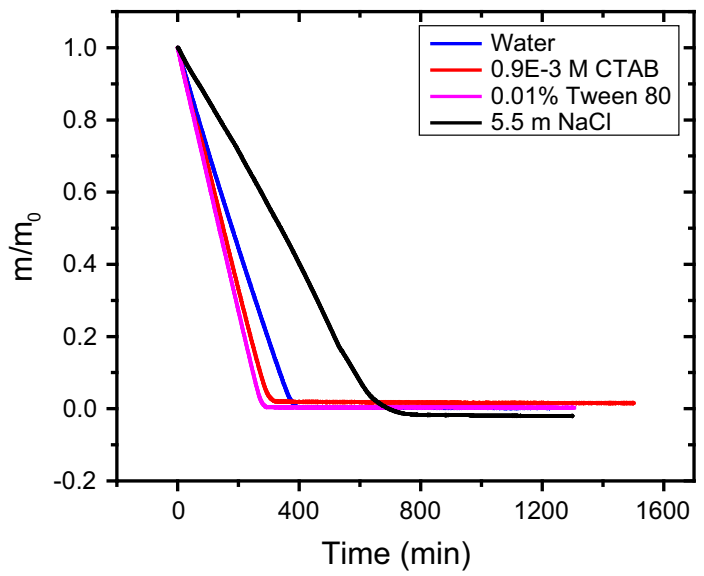

In order to single out the influence of surfactants alone on the drying in stones, we also performed some experiments with pure water and aqueous surfactant solutions. As shown in Fig. 4, samples saturated with pure water and with water-surfactant solutions dry at about the same constant rate $\mathrm{d} m / \mathrm{d} t \sim 0.5 \mathrm{mg} / \mathrm{min}$ until they are completely dried (the time when there is no measurable change in mass anymore). The difference in evaporation rate of water compared to the $\mathrm{NaCl}$ solution is due to the lower vapor pressure above $\mathrm{NaCl}$ solution compared to that of water.

The results confirm that although the presence of surfactants in the solution lowers the surface tension, it does not influence the evaporation rate of water and their main effect is on the salt precipitation dynamics. 


\subsubsection{Drying at Winter Weather Conditions (RH 20\%)}

The drying experiments were also conducted for a RH of $20 \%$. We find that, contrary to what happens at a $\mathrm{RH}=60 \%$ (where the drying of the sample happens at a constant rate throughout the whole process), for $\mathrm{RH}=20 \%$ the drying slows down with time (Fig. 5). Although it is initially faster due to the lower $\mathrm{RH}$, we find that the total drying time at $\mathrm{RH} 20 \%$ is longer than at RH $60 \%$.

Although the difference between the two relative humidities is counterintuitive, similar results have in fact been reported previously (Desarnaud et al. 2015; Gupta et al. 2014). As explained by Desarnaud et al. (2015), the slower drying seen at lower relative humidities arises because the initially faster evaporation leads to rapid precipitation of $\mathrm{NaCl}$ crystals at the surface, which by growing laterally forms a crust that eventually leads to a loss of capillary connections between the surface and bulk. Subsequently, when the surface is completely covered with a thick crust of salt, water vapor then needs to diffuse through it, in contrast to direct evaporation from the surface of the stone. This explanation is again confirmed by our SEM investigation of the stone surface after $\mathrm{NaCl}$ drying in $\mathrm{RH} 20 \%$ (Fig. 6): The salt crystallizes into a low-porosity crust (pores size $2-5 \mu \mathrm{m}$ ) covering the stone pores and thus blocking evaporative surface area.

The presence of surfactants combined with rapid evaporation (at low relative humidity) clearly accelerates the development of a crust. As it is shown in Fig. 5 (right), in the initial stage, drying appears to be unaffected by the surfactants and leads to the rapid evaporation of
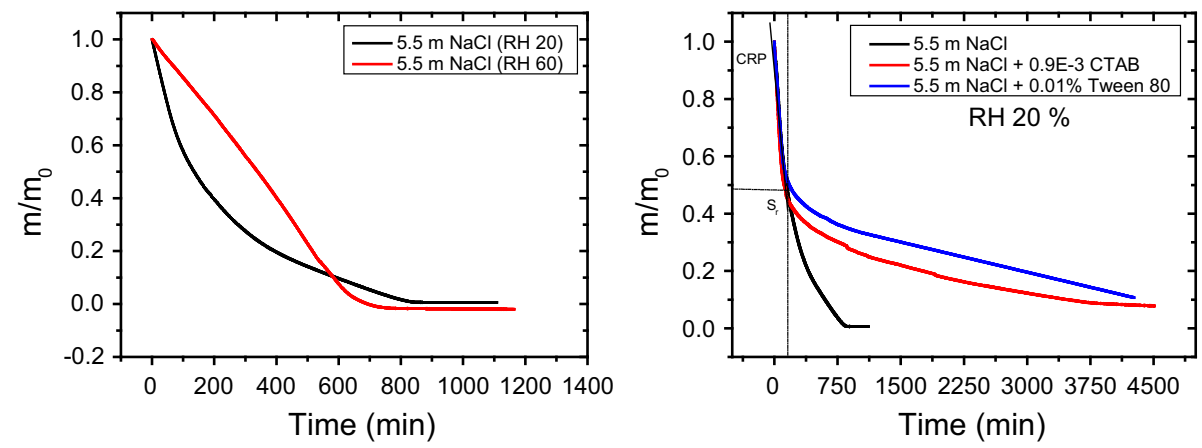

Fig. 5 Left: dimensionless evolution $\left(\mathrm{m} / \mathrm{m}_{0}\right)$ of mass of water when Prague sandstone saturated with sodium chloride solution dries at RH 20\% (black line) and RH 60\% (red). Right: NaCl solution with (red: CTAB; blue: Tween 80) and without (black) surfactant solutions at RH 20\%. (In the first capillary stage $\mathrm{d} m / \mathrm{d} t \sim 0.7 \mathrm{mg} / \mathrm{min}$ )

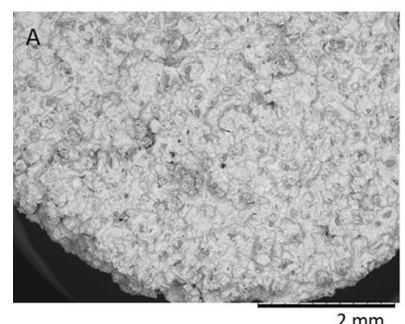

$2 \mathrm{~mm}$

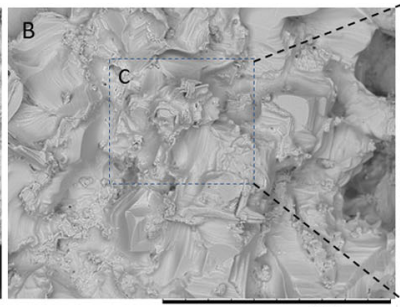

$500 \mu \mathrm{m}$

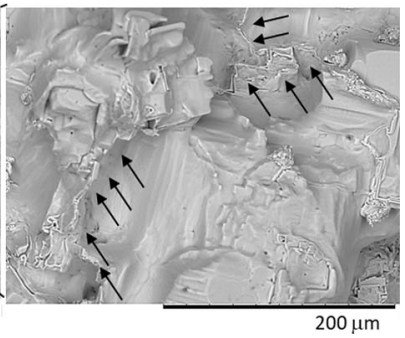

Fig. $6 \mathrm{SEM}$ images of efflorescence of $\mathrm{NaCl}+\mathrm{CTAB}$ solution dried in Prague sandstone at $\mathrm{RH} 20 \%$. The junctions, between different crystallites, which are grown laterally, are shown by arrows on the right 
Fig. 7 Mass of evaporated water as a function of the square root of time (for diffusive regime) for $\mathrm{NaCl}+\mathrm{CTAB}$ dried at $\mathrm{RH}=60 \%$ (black symbols) and $20 \%$ (red symbols)

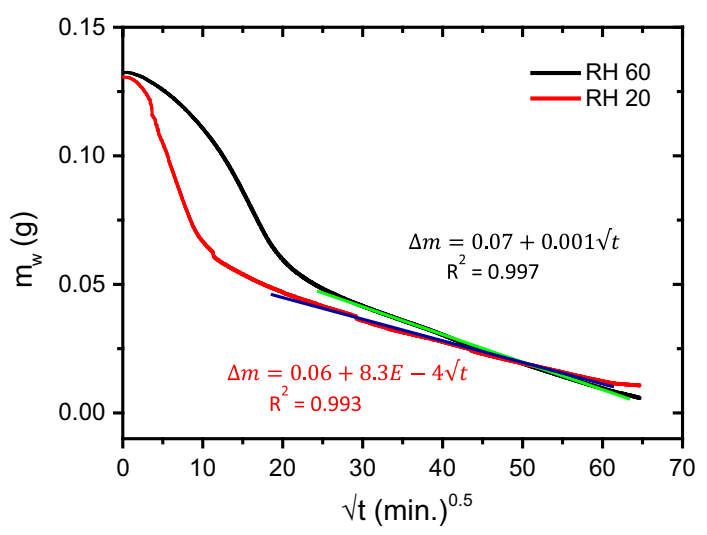

about $60 \%$ of the water that was initially present. At later times (the 'crust stage'), the drying process slows down much earlier compared to pure $\mathrm{NaCl}$. This can be understood from the observation that the presence of surfactants (as impurities) combined with rapid evaporation leads to the formation of more crystallites, each of them grows laterally and makes quickly an extensive crust of salt, thereby blocking the pores more rapidly (Fig. 6).

In Fig. 7, the mass of the evaporated water as a function of the square root of time is compared for a given surfactant $(\mathrm{NaCl}+\mathrm{CTAB}$ solution) at different relative humidities $(\mathrm{RH}=60 \%$ and $20 \%$ ). The data fits well to the model of diffusive transport (Eq. 1) for both relative humidities. It is important to note that the rate of evaporation is also very close for both cases; if the salt solution in the stone was still connected to the upper surface of the crust, significant differences should be seen for the two different relative humidities. This is clearly not the case, so transport of water from the surface of the stone to vapor phase above the stone is apparently not the rate-limiting step for evaporation. Additionally, the results reveal that the surfactants play a major role as crystallization modifiers rather than as wetting agents. The different crystallization patterns caused by the addition of surfactant affect the drying mechanism of the solutions.

\subsection{Fontainebleau Sandstone (Low Porosity)}

\subsubsection{Drying at Summer Weather Conditions (RH 60\%)}

The influence of the microstructure of the stone on the drying of salt and surfactant solutions has been investigated by repeating the experiments in Fontainebleau sandstone. At RH 60\%, like the stone with higher porosity, in Fig. 8, the pure $\mathrm{NaCl}$ solution dries at the same constant drying rate $(\mathrm{d} m / \mathrm{d} t=0.2 \mathrm{mg} / \mathrm{min})$, until the sample is completely dry. As the evaporation takes place from liquid at the surface, the evaporation flux is then controlled by diffusion of water molecules into the air and is independent of the characteristics of the stone. In the subsequent drying experiments using surfactants, CTAB and Tween 80 , the evaporation dynamics remain unchanged, that is, the drying proceeds with a constant rate period until a very low residual saturation $\left(S_{\mathrm{r}}\right)$ is reached.

In order to understand the much smaller influence of surfactants on the drying kinetics in Fontainbleau sandstone, analysis of the scanning electron microscopy images of the stone surface was done at the end of drying. For pure $\mathrm{NaCl}$ solution, a patchy crust with cauliflower- 
Fig. 8 Time evolution of the saturation $\left(m_{t} / \mathrm{m}_{0}\right)$ in Fontainebleau sandstone at $\mathrm{RH}$ 60\%: black: pure $\mathrm{NaCl}(\mathrm{d} m / \mathrm{d} t=$ $0.24 \mathrm{mg} / \mathrm{min}$ ); red: with CTAB; blue: with Tween 80
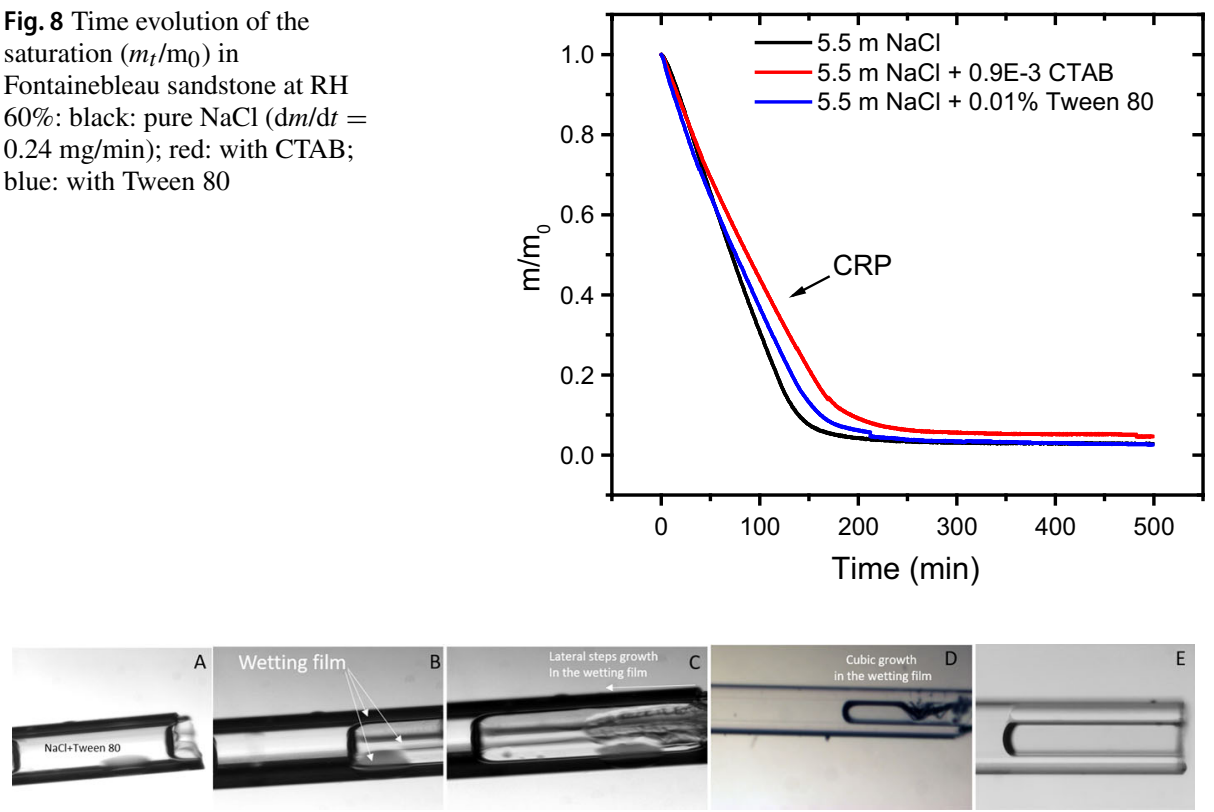

Fig. 9 Evaporation of $\mathrm{NaCl}+$ Tween 80 solutions in square microcapillaries. a, b With evaporation of the liquid, the contact line remains pinned and wetting films are formed in the corners. $\mathbf{c}$ Lateral crystal growth in the film at low $\mathrm{RH}=20 \%$, $\mathbf{d}$ cubic growth in the film at high $\mathrm{RH}=60 \%$. e Pure $\mathrm{NaCl}$ solution: No films are observed with the receding of the liquid

like crystalline structures was observed; similar to what is seen for the Prague sandstone, clearly, the pores remain open during evaporation. In the presence of CTAB and Tween 80, although evaporative surface of pores remains open, the precipitation of well-defined cubic crystals can be seen on the surface. The reason behind the formation of such cubic crystals might be that when surfactants are added to the solution, because of the lower surface tension of the liquid, the latter can stay pinned and consequently during the retraction of the liquid with evaporation, the wetting films can stay stable on a solid surface. This hypothesis has been confirmed by doing some experiment in model square capillaries (Fig. 9). As can be observed, when surfactants are present in the salt solution, wetting films are created when the liquid retracts in contrast with pure sodium chloride solution and crystallization occurs rather in the film than at the meniscus. For the Fontainebleau sandstone, the ratio of voids area to the total area is much lower (Fig. 10) and the surface of grains can be covered by such wetting films. A slow evaporation (RH 60\%), subsequently, induces the homogenous growth of crystallites in the form of well-shaped cubic crystals instead of precipitation of small microcrystallites as cauliflower structures. Hence, in both cases, the pores of the stone remain open enabling the persistence of a single drying stage until all the water has evaporated from the sample (Fig. 11).

The very limited influence of surfactants on drying kinetics is also related to the characteristics of the stone: Small pores and low porosity allow the salt solution to come to the surface of the stone by capillary forces where lower porosity leaves more surface area for the evaporation. The larger surface area also means that there is enough solid surface for the salt to crystallize without blocking the pores. 

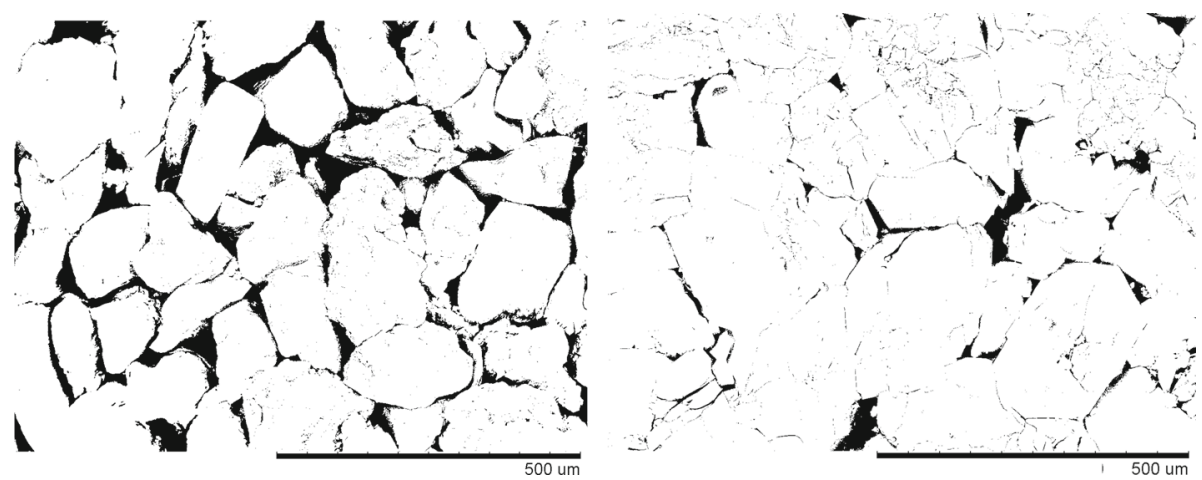

Fig. 10 Visualization of solid area and pore area from SEM images of left: Prague sandstone (pore area 12\%) and right: Fontainebleau sandstone (pore area $\sim 3 \%$ )
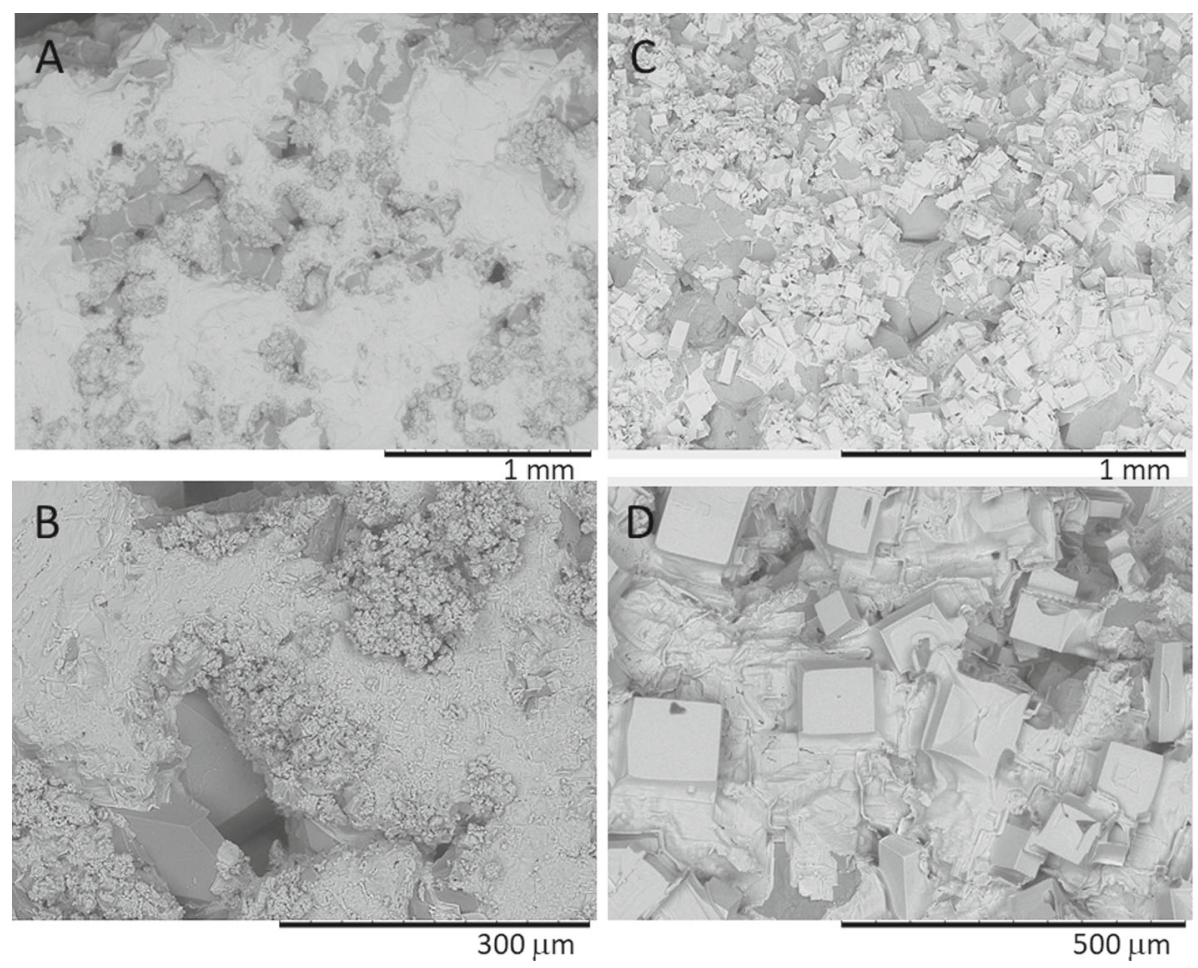

Fig. 11 Crystallization pattern from salt solutions dried in Fontainebleau sandstone at $\mathrm{RH} 60 \%$. a, b pure $\mathrm{NaCl}$ solution $\mathbf{c}, \mathbf{d ~ N a C l}+\mathrm{CTAB}$ solution

\subsubsection{Drying at Winter Weather Conditions (RH 20\%)}

When the same experiments are done at lower RH (20\%) [Fig. 12 (left)], after a constant rate period the drying slows down gradually with evaporation time. However, in contrast to Prague sandstone, where surfactants further slow down the evaporation in the second and third stages, in Fontainebleau sandstone, no such influence is observed. Since the porosity of 

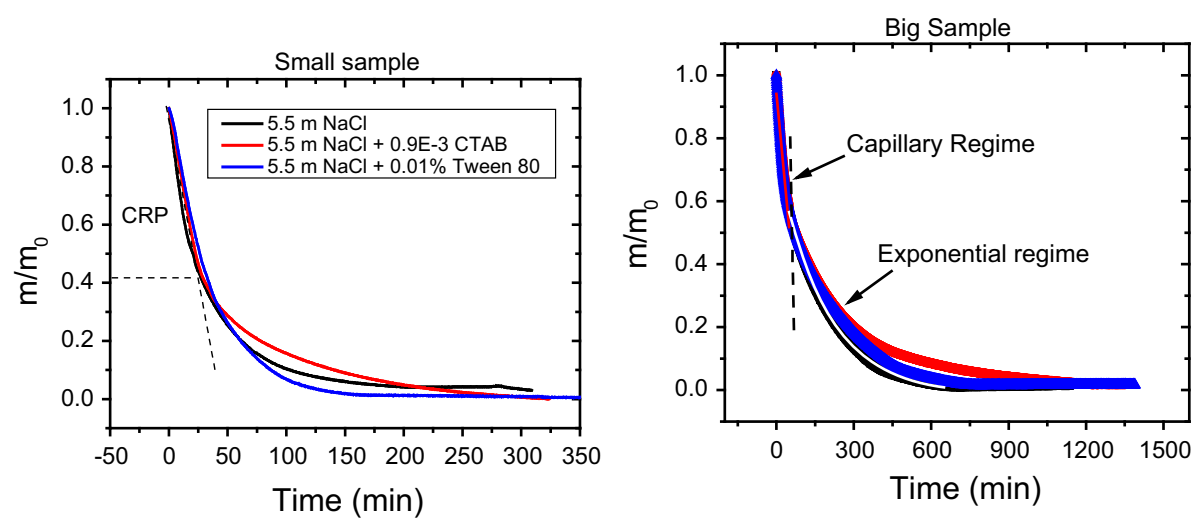

Fig. 12 Comparison of the evaporation in different sample size: left $) 8 \times 9 \mathrm{~mm}\left(V_{\mathrm{p}} / S_{\mathrm{e}}=0.12\right)$ right $) 1.5 \times$ $1.5 \mathrm{~cm}\left(V_{\mathrm{p}} / S_{\mathrm{e}}=0.45\right)$ at RH $20 \%$. (Capillary regime: $\mathrm{m} / \mathrm{m}_{0}=0.94-0.008 t ; R^{2}=0.95$; exponential regime: $\left.\mathrm{m} / \mathrm{m}_{0}=-0.014+0.75 \exp (-0.005 t) ; R^{2}=0.99\right)$
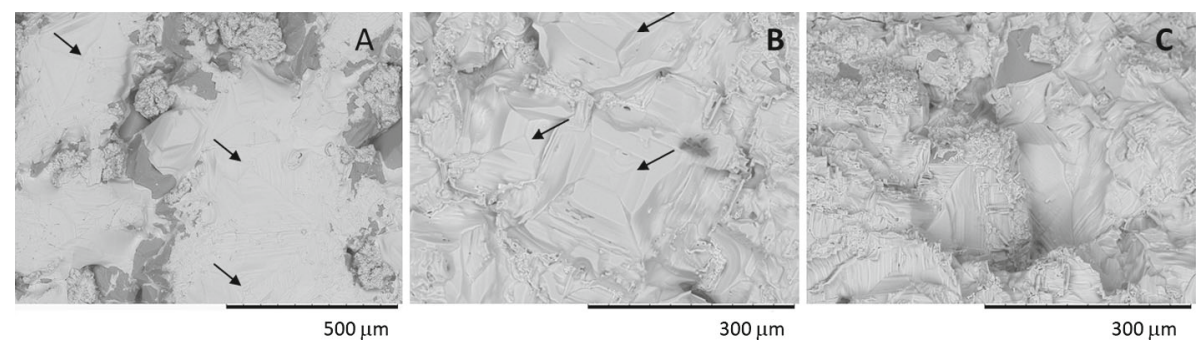

Fig. 13 SEM images of efflorescence formed from a $\mathrm{NaCl}$ solution and $\mathbf{b} \mathrm{NaCl}+\mathrm{CTAB} \mathrm{C}) \mathrm{NaCl}+\mathrm{Tween} 80$ dried in Fontainebleau sandstone at RH 20\%. The lateral steps growth of adjacent microcrystallites are shown with arrows

the Fontainebleau sandstone is low, it contains less salt solution and thus the crust could be less pronounced. However, taking larger Fontainebleau samples $(D=1.5 \mathrm{~cm}, L=1.5 \mathrm{~cm})$ with twice the volume-to-surface ratio, Fig. 12 (right), the results show again a similar drying rate with and without surfactants. The results suggest that for all the systems, the small pores maintain a capillary flux high enough toward the surface compared to the evaporative flux. On the other hand, the fast evaporation induces the rapid growth of crystals on the surface of the stone (Fig. 3), forming a crust. In agreement with this observation, the mass loss from evaporation becomes exponential in time.

This is once more confirmed by the SEM images of the crust formed on the top of the stone after drying with and without surfactants. Despite the lateral growth mechanism of crystals on the surface of grains, the pores responsible to bring solution to interface remain open with and without surfactants (Fig. 13).

\section{Conclusions}

The mechanism of salt crust formation is shown to be due to the lateral steps growth of crystallites at the surface with defective junctions between them. Here, we show that such 
mechanism of growth occurs more readily when the drying process is accelerated by a low RH or when impurities such as surfactants are added to the solution. In many practical situations, detergents are used to clean salt-contaminated stones. Our results reveal that after adding a cationic or nonionic surfactant, the drying rate initially is unchanged but can slow down dramatically due to the formation of a salt crust even at high relative humidity. When this happens, the presence of the surfactant increases the total drying time when compared to pure $\mathrm{NaCl}$ solutions dried under the same conditions.

Compared to pure water or pure salt solution, the addition of surfactants reduces the equilibrium capillary height due to the lower surface tension. However, during drying, surfactants can rather stabilize the wetting film during the retraction of the liquid and therefore do not change the evaporation rate at the surface during the constant rate period. Hence, the impact of the surfactants is rather that of a crystallization modifier.

For stones with high porosity, with lower solid surface area, these additives can exacerbate the salt crust effect: By modifying the crystallization dynamics of the $\mathrm{NaCl}$ during drying, the water evaporation switches from being limited by capillary action through pores to being limited by diffusion through the salt crust covering the surface and subsurface. The water loss due to evaporation in the third stage of drying after the crust formation scales with the square root of time for both relative humidities, as is expected for diffusion-limited vapor transport through the crust.

For stones with low porosity, with much higher solid surface area $(>90 \%)$, the surfactants stabilize the wetting film covering the grains and induce a homogeneous crystals precipitation on the surface of grains. In addition, because of higher capillary flux due to smaller pores, the pores remain open at the surface.

Lowering the RH in all cases promotes the lateral growth of crystals, which will decelerate the evaporation due to the gradual formation of crust.

Surfactants are often used as cleaning agents. Slow drying can be detrimental for building materials as it makes them more susceptible to frost and biological damage. The properties of cleaning products should therefore be carefully considered in the context of conservation strategies in relation to the petrophysical properties of the stone and the environmental conditions.

Open Access This article is distributed under the terms of the Creative Commons Attribution 4.0 International License (http://creativecommons.org/licenses/by/4.0/), which permits unrestricted use, distribution, and reproduction in any medium, provided you give appropriate credit to the original author(s) and the source, provide a link to the Creative Commons license, and indicate if changes were made.

\section{References}

Afsar-Siddiqui, A.B., Luckham, P.F., Matar, O.K.: Dewetting behavior of aqueous cationic surfactant solutions on liquid films. Langmuir 20(18), 7575-7582 (2004)

Beacham, D.R., Matar, O.K., Craster, R.V.: Surfactant-enhanced rapid spreading of drops on solid surfaces. Langmuir 25(24), 14174-14181 (2009)

Bergstad, M., et al.: The influence of $\mathrm{NaCl}$ concentration on salt precipitation in heterogeneous porous media. Water Resour. Res. 53(2), 1702-1712 (2017)

Chen, J., et al.: Impact of surfactants on the crystallization of aqueous suspensions of celecoxib amorphous solid dispersion spray dried particles. Mol. Pharm. 12(2), 533-541 (2015)

Coussot, P.: Scaling approach of the convective drying of a porous medium. Eur. Phys. J. B 15(3), 557-566 (2000)

Derluyn, H., Moonen, P., Carmeliet, J.: Deformation and damage due to drying-induced salt crystallization in porous limestone. J. Mech. Phys. Solids 63, 242-255 (2014) 
Desarnaud, J., et al.: Drying of salt contaminated porous media: effect of primary and secondary nucleation. J. Appl. Phys. 118(11), 114901 (2015)

Desarnaud, J., et al.: The pressure induced by salt crystallization in confinement. Sci. Rep. 6, 30856 (2016)

Desarnaud, J., Bertrand, F., Shahidzadeh-Bonn, N.: Impact of the kinetics of salt crystallization on stone damage during rewetting/drying and humidity cycling. J. Appl. Mech. 80(2), 020911 (2013)

Eloukabi, H., et al.: Experimental study of the effect of sodium chloride on drying of porous media: the crusty-patchy efflorescence transition. Int. J. Heat Mass Transf. 56(1-2), 80-93 (2013)

Espinosa-Marzal, R.M., Scherer, G.W.: Advances in understanding damage by salt crystallization. Acc. Chem. Res. 43(6), 897-905 (2010)

Flatt, R.J., et al.: Chemo-mechanics of salt damage in stone. Nat. Commun. 5, 4823 (2014)

Flatt, R.J., Steiger, M., Scherer, G.W.: A commented translation of the paper by C.W. Correns and W. Steinborn on crystallization pressure. Environ. Geol. 52(2), 187-203 (2007)

Grementieri, L., et al.: Numerical simulation of salt transport and crystallization in drying Prague sandstone using an experimentally consistent multiphase model. Build. Environ. 123, 289-298 (2017)

Guglielmini, L., et al.: Drying of salt solutions in porous materials: intermediate-time dynamics and efflorescence. Phys. Fluids 20(7), 077101 (2008)

Gupta, S., et al.: Paradoxical drying of a fired-clay brick due to salt crystallization. Chem. Eng. Sci. 109, 204-211 (2014)

Le Bray, Y., Prat, M.: Three-dimensional pore network simulation of drying in capillary porous media. Int. J. Heat Mass Transf. 42(22), 4207-4224 (1999)

Lubelli, B., van Hees, R.P.J.: Effectiveness of crystallization inhibitors in preventing salt damage in building materials. J. Cult. Herit. 8(3), 223-234 (2007)

Myatt, G.J., et al.: The influence of surfactants and water-soluble polymers on the crystallization of zeolite NaA. Zeolites 14(3), 190-197 (1994)

Nachshon, U., et al.: Combined evaporation and salt precipitation in homogeneous and heterogeneous porous media. Water Resour. Res. 47(3), W03513 (2011)

Qazi, M.J., et al.: Influence of surfactants on sodium chloride crystallization in confinement. Langmuir 33(17), 4260-4268 (2017)

Rad, M.N., et al.: Effects of grain and pore size on salt precipitation during evaporation from porous media. Transp. Porous Media 110(2), 281-294 (2015)

Rodriguez-Navarro, C., Doehne, E., Sebastian, E.: Influencing crystallization damage in porous materials through the use of surfactants: experimental results using sodium dodecyl sulfate and cetyldimethylbenzylammonium chloride. Langmuir 16(3), 947-954 (2000)

Sghaier, N., Prat, M.: Effect of efflorescence formation on drying kinetics of porous media. Transp. Porous Media 80(3), 441-454 (2009)

Shahidzadeh-Bonn, N., et al.: Salt crystallization during evaporation: impact of interfacial properties. Langmuir 24(16), 8599-8605 (2008)

Shahidzadeh-Bonn, N., Azouni, A., Coussot, P.: Effect of wetting properties on the kinetics of drying of porous media. J. Phys. Condens. Matter 19(11), 112101 (2007)

Shokri-Kuehni, S.M.S., et al.: Impact of type of salt and ambient conditions on saline water evaporation from porous media. Adv. Water Resour. 105, 154-161 (2017)

Sonin, A.A., Palermo, T., Lubek, A.: Effect of a dispersive surfactant additive on wetting and crystallisation in a system: water-oil-metal substrate. Application to gas hydrates. Chem. Eng. J. 69(2), 93-98 (1998)

Steiger, M.: Crystal growth in porous materials-II: influence of crystal size on the crystallization pressure. J. Cryst. Growth 282(3-4), 470-481 (2005)

Veran-Tissoires, S., Marcoux, M., Prat, M.: Discrete salt crystallization at the surface of a porous medium. Phys. Rev. Lett. 108(5), 054502 (2012)

Vojtková, H.: Algae and their biodegradation effects on building materials in the Ostrava industrial agglomeration. IOP Conf. Ser. Earth Environ. Sci. 92(1), 012073 (2017)

Winkler, E.M.: Frost damage to stone and concrete: geological considerations. Eng. Geol. 2(5), 315-323 (1968)

Yang, X., et al.: Effect of impurity on the lateral crystal growth of L-Alanine: a combined simulation and experimental study. Ind. Eng. Chem. Res. 51(45), 14845-14849 (2012)

Yiotis, A.G., et al.: Effect of liquid films on the isothermal drying of porous media. Phys. Rev. E 68(3), 037303 (2003) 